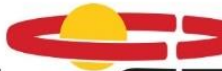 \\ UnC=UB \\ Centro Universitário de Brasília \\ CENTRO UNIVERSITÁRIO DE BRASÍLIA - UniCEUB \\ PROGRAMA DE INICIAÇÃO CIENTÍFICA
}

GABRIELA LIMA DE ALCÂNTARA

MARCOS VINICIUS DA SILVA BOITRAGO

EFEITOS DA PERDA DE PESO AGUDA EM ATLETAS DE COMBATE

BRASÍLIA 


\section{Unic: \\ Centro Universitário de Brasília}

GABRIELA LIMA DE ALCÂNTARA

MARCOS VINICIUS DA SILVA BOITRAGO

\section{EFEITOS DA PERDA DE PESO AGUDA EM ATLETAS DE COMBATE}

Relatório final de pesquisa de Iniciação Científica apresentado à Assessoria de Pós-Graduação e Pesquisa.

Orientador: Marcio Oliveira

BRASÍLIA 


\section{DEDICATÓRIA}

Aos nossos pais, por sempre terem proporcionado o incentivo incondicional para que pudesse realizar e finalizar este trabalho, a graduação em fisioterapia e medicina e tantas outras atividades. Vocês são exemplo para nós, jamais teria conseguido chegar até aqui sem vocês. 


\section{AGRADECIMENTOS}

Á Deus, que está acima de todas as coisas, que sempre esteve conosco em cada passo dado.

Aos nossos pais, por não medirem esforços para me ajudar a realizar nossos sonhos.

Ao Prof. Márcio Oliveira, um agradecimento especial, pela pessoa incrível que é, pelos ensinamentos diários.

Á todos os voluntários do estudo que concordaram em participar da pesquisa, desde as avaliações e intervenções.

Ao Centro Universitário de Brasília - UniCEUB e Faculdade de Ciências da Saúde - FACES pelo apoio para o desenvolvimento e conclusão deste trabalho.

Ao Instituto de Pesquisa e Ensino do Hospital Ortopédico de Medicina Especializada IPE/HOME pelo apoio para o desenvolvimento deste trabalho. 


\title{
EFEITOS DA PERDA DE PESO AGUDA EM ATLETAS DE COMBATE
}

\author{
Marcos Vinicius da Silva Boitrago - UniCEUB, PIC HOME, aluno bolsista \\ marcos.boitrago@sempreceub.com
}

\author{
Gabriela Lima de Alcântara - UniCEUB, PIC HOME, aluna voluntário \\ gabriela.alcantara@sempreceub.com
}

Marcio de Paula e Oliveira - UniCEUB, professor orientador

marcio.Oliveira@ceub.edu.br

\section{RESUMO}

\begin{abstract}
Sabe-se que atletas de modalidades de combate, especialmente o MMA na atualidade, reduzem o peso corporal para se adequarem à categoria desejada. Para atingirem esse objetivo, o método mais utilizado é a desidratação aguda. A desidratação é definida como perda de água do organismo. Alguns atletas chegam a perder $10 \mathrm{~kg}$ na semana da competição - às custas da perda de água corporal, glicogênio muscular e, em menor índice, gordura e massa muscular. Essa prática expõe o corpo a problemas como mudanças no balanço osmótico, que produzem diminuição na força muscular, facilitam o aparecimento de câimbras e reduzem a qualidade de execução dos movimentos, diminuindo a performance geral do atleta. Além disso, ocorrem alterações psicológicas como estresse e fadiga mental. Essa progressão poderá até mesmo levar o atleta ao óbito, como registrado em eventos nacionais e internacionais. Diante do exposto o objetivo do presente estudo foi avaliar o impacto da perda de peso aguda por desidratação em atletas profissionais de Jiu-Jitsu. A pesquisa foi desenvolvida no Centro Universitário de Brasília - UniCEUB, em parceria com o Instituto de Pesquisa e Ensino do Hospital HOME/Brasília-DF. Foi realizado um ensaio clínico controlado não randomizado com 10 atletas de alto rendimento com média de idade $32( \pm 6,34)$ anos, peso $74,90( \pm 9,24) \mathrm{kg}$, estatura $170,10( \pm 8,99) \mathrm{cm}$, que competiram na Copa Born to Fight de Submission. A pesquisa foi realizada em três etapas: avaliação pré-intervenção (mensuração do peso e percentual de gordura corpórea por bioimpedância; exames laboratoriais hemograma, exame de urina, cortisol salivar; avaliação da força de preensão manual; avaliação da resposta cognitiva), perda de peso (em sauna úmida com redução de $3 \%$ do peso corporal) e avaliação pós-intervenção (repetição dos testes). A análise dos resultados demonstrou uma diminuição significante da força de preensão manual e da variável cognitiva de reação simples, ou seja, após a intervenção os atletas ficaram mais lentos.
\end{abstract}

Palavras-chave: Desidratação. Atletas. Artes marciais. 


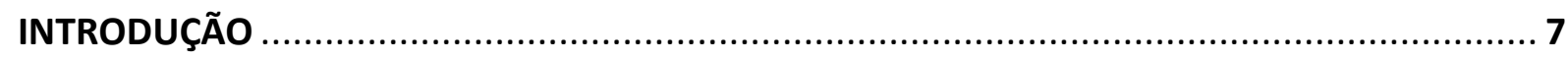

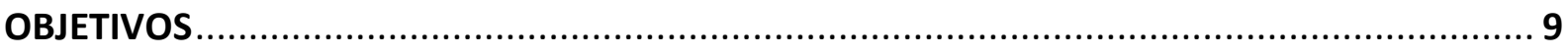

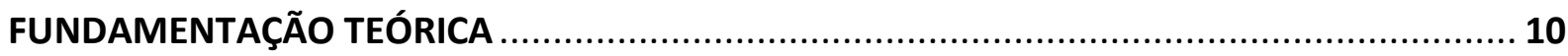

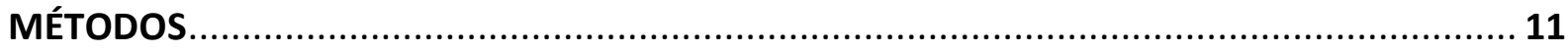

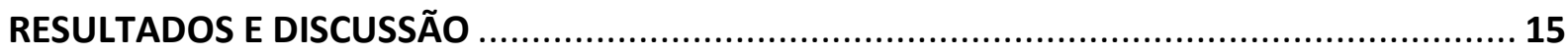

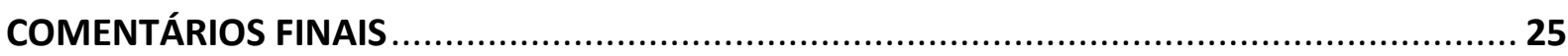

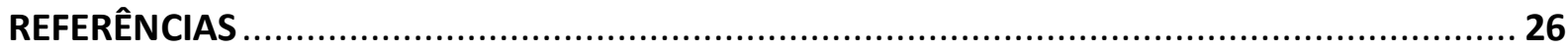




\section{INTRODUÇÃO}

As modalidades de esporte de combate (MEC) são formas "esportivizadas" das artes marciais, possuindo características comuns às demais modalidades esportivas ${ }^{1}$.

No Ocidente, os primeiros confrontos atléticos envolvendo ações de lutas, que se aproximam das atuais MEC, ocorreram na Grécia Antiga. A luta, o pugilato e o pancrácio faziam parte dos Jogos Olímpicos e dos outros jogos disputados pelas cidades-estados gregas ${ }^{2}$.

O termo "combate" é oriundo dos tempos que essas atividades eram feitas exclusivamente nos campos de treinamento militar, por tropas do exército e em campos de batalha. Dentro do movimento esportivo formal podemos observar vários esportes como boxe, luta olímpica, esgrima, judô, caratê e outros que possuem as seguintes características: regras internacionais padronizadas para a competição, recompensas financeiras, altos níveis de treinamento, desempenho e especialização dos atletas, como ocorrem em comum com outros esportes, a exemplo do futebol ou do tênis ${ }^{3}$.

As modalidades de luta apresentam como critérios para classificar os atletas o nível técnico (graduação/faixa), a idade e o peso. A fim de se encaixar em disputas que possam Ihes proporcionar determinada vantagem, por vezes os atletas tentam alterar as variáveis que os classificam, sendo as alterações bruscas no peso corporal o principal manejo realizado ${ }^{4}$.

Segundo Hirschbruch \& Carvalho ${ }^{5}$, os lutadores em geral utilizam vários métodos para perder peso rápido, como: restrição alimentar, privação de líquidos, treinarem com uniformes revestidos de borracha, forçar o vômito e ingerir laxantes. A maior parte dos atletas que competem em certas faixas de peso começam a restringir suas dietas e a reduzir sua ingestão de líquidos na semana anterior a pesagem e intensificam essas medidas conforme esta data se aproxima ${ }^{6}$. No último dia antes da pesagem, muitos atletas jejuam e alguns desidratam de tal maneira que sugam cubos de gelo para prevenir excesso de secura em suas bocas ${ }^{7}$.

Vale ressaltar que esportes de luta estão entre os mais populares mundialmente olímpicos ou não e a maioria dos estudos a respeito das práticas de perda de peso nesta modalidade se baseia no relato dos atletas, o que pode não representar a verdadeira prevalência da rápida perda de peso ${ }^{8}$. Há relatos de que as elevadas perdas de peso ocorridas em dias que precedem as competições, gravitam em torno de $10 \mathrm{~kg}$, o que é possível graças à 
perda de água, glicogênio muscular e, em menor proporção, gordura e massa muscular. 0 célebre caminho para atingir o peso desejado é o desidratar; todavia, tais manobras oferecem riscos à saúde, desde a perda agressiva de peso como a consequência de chegar à morte ${ }^{9}$.

São vários os elementos fisiológicos que sofrem interferência durante um quadro de desidratação em uma competição ou treinamento, alterando de forma significativa a qualidade da atividade desempenhada. Dentre as alterações podemos citar: mudanças no balanço osmótico produzindo modificações no equilíbrio iônico entre os meios intra e extracelular, que por sua vez afetam a capacidade de transmissão nervosa ou contração muscular, facilitando então o aparecimento de cãibras e redução na qualidade de execução dos movimentos. Além disso, há modificações cardiovasculares e no controle da temperatura corporal. Todos esses fatores agindo, além de prejudicarem a performance do atleta poderão colocar em risco a integridade do mesmo quando a perda hídrica for entre 9 e $12 \%{ }^{9}$.

Dessa forma, o presente estudo teve por objetivo avaliar os efeitos da perda de peso aguda por desidratação em sauna em atletas de combate de alto rendimento. 
OBJETIVO GERAL

Avaliar o impacto da perda de peso aguda por desidratação em atletas profissionais de Jiu-Jitsu.

\section{OBJETIVO ESPECÍFICO}

Analisar e comparar a força muscular após as duas modalidades propostas.

Analisar e comparar o impacto cognitivo após as duas modalidades propostas.

Analisar e comparar o estado hidroeletrolítico após as duas modalidades de propostas.

Analisar e comparar o peso e quantidade de água corpórea após as duas modalidades de propostas. 


\section{FUNDAMENTAÇÃO TEÓRICA}

Percebe-se, atualmente, que esportes de combate são extremamente populares. Representam cerca de $25 \%$ das medalhas olímpicas e movem milhões de telespectadores ${ }^{38}$. Sendo assim, cada vez mais atletas engajam-se a praticar essas modalidades e, consequentemente, a competir. Ademais, tais práticas dividem seus atletas em categorias de faixa/graduação, idade, sexo e peso ${ }^{4}$, o que leva atletas a diminuir seu peso de forma aguda, para adquirir vantagens sobre seu oponente ${ }^{4,13,40}$. As práticas utilizadas variam entre restrição alimentar e hídrica, até o uso de laxantes e desidratação em sauna, sendo essa última, objeto do presente estudo. Vale ressaltar que tal prática, apesar de amplamente difundida, pode danificar a saúde do atleta.

Houston, Marrin, Green e Thomson (1981) já documentavam mudanças fisiológicas geradas pela perda de peso rápida em atletas, onde destacaram diminuição nos estoques de glicogênio muscular, diminuição do torque muscular ${ }^{40}$. Em adição, é descrito que há diminuição na força de preensão manual em judocas que se submetiam a este processo ${ }^{42}$. Além disso, Pinto, Möller e Alves (2019) documentaram que atletas que se submetem a essa prática referem sentir queda no desempenho em competição devido à perda de peso ${ }^{43}$.

Diversos estudos reportam, ainda, efeitos dessa diminuição acelerada do peso em parâmetros cognitivos. Franchini, Brito e Artioli (2012), por exemplo, expõe pesquisas em que atletas apresentaram diminuição na memória de curto prazo, assim como no vigor, na concentração e na autoconfiança, além de aumento na confusão, raiva, fadiga, depressão e isolamento social após rápida perda de peso ${ }^{13}$.

A respeito da desidratação, a literatura é certa: esse estado, por si só, é deletério e, associado à prática de esportes, pode ser extremamente perigoso ${ }^{9}$. Félix e Chaves (2015) destacam que a desidratação tem efeitos, principalmente, em processos fisiológicos (aumento de temperatura corporal e redução no volume sanguíneo, por exemplo) $)^{44}$.

Por fim, pouco se sabe a respeito de um protocolo seguro e eficaz de perda de peso nestes casos. Alguns pesquisadores abordam a perda de peso de maneira mais gradual, enquanto outras estratégias como redução no consumo de carboidratos e jejum intermitente ${ }^{42}$. De maneira geral, contudo, destaca-se a necessidade de mais estudos para analisar as diversas variáveis envolvidas neste processo ${ }^{13,39-44}$. 


\section{MÉTODOS}

Foi realizado um ensaio clínico controlado não randomizado com 10 atletas que faziam parte do card principal da Copa UniCEUB Born to Fight de Submission e Jiu-Jitsu, realizado no mês de novembro de 2019, em Brasília/DF.

Foram considerados como critérios de inclusão ter a idade compreendida entre 18 e 45 anos, a graduação mínima de faixa marrom em lutas de grappling (jiu-jitsu, judô ou luta livre), a participação frequente em competições de caráter nacional, não fazer uso de medicamentos que pudessem interferir nos resultados e estar dentro da política de controle de substâncias no esporte da Agência Mundial Antidoping (WADA). Poderiam ser de ambos os sexos. Foram excluídos aqueles que não participaram de todas as etapas da pesquisa.

A pesquisa foi realizada em 3 etapas: avaliação pré-intervenção, perda de peso (intervenção) e avaliação pós-intervenção. Os procedimentos estão descritos abaixo:

\section{Critérios de avaliação}

As avaliações foram feitas na véspera da competição em um ambiente adaptado, que incluía a recepção, área de descanso, vestiários e sauna. Inicialmente os atletas foram admitidos e registrados os seus dados pessoais, histórico de lesões e - estado geral de saúde frequência cardíaca, pressão arterial, saturação periférica de oxigênio, estatura e peso. Em seguida foram explicados detalhadamente todos os procedimentos e foi assinado o Termo de Consentimento Livre e Esclarecido (TCLE).

As condutas abaixo foram realizadas anteriormente e após a desidratação:

\section{Bioimpedância}

Para a coleta de dados de bioimpedância foi utilizado o aparelho de monitoramento de gordura corporal da marca Omron ${ }^{\circledR}$ modelo HBF 306. O atleta foi posicionado de pé segurando o equipamento com as duas mãos sob a superfície dos eletrodos e os braços estendidos à frente com intuito de formar um ângulo de 90ำ com o tronco, possibilitando assim a passagem de corrente elétrica pelos membros superiores ${ }^{10}$. Foram utilizados os valores de percentual total de gordura corporal. 


\section{Exame analítico do sedimento urinário (EAS)}

Coletou-se o jato médio da primeira urina da manhã e logo após o processo de desidratação. O exame clínico foi realizado em três etapas: caracteres gerais (propriedades físicas - densidade e ph), pesquisa de elementos anormais (pesquisa química - proteínas, glicose, corpos cetônicos, bilirrubina, urobilinogênio, nitrato, hemácias e leucócitos) e sedimentoscopia (feita por meio de microscopia manual a partir da metodologia da Norma Brasileira: Laboratório Clínico - Requisitos e Recomendações para Exame de Urina (2005).

\section{Cortisol salivar}

Foi realizada no recipiente (Salivette ${ }^{\circledR}$ ) fornecido pelo Laboratório Sabin (Brasília/DF). Os horários de cada coleta foram identificados individualmente e indicados em cada tubo de coleta. O método de dosagem foi a eletroquimioluminescência.

\section{Força de preensão palmar}

Foi avaliada com o dinamômetro hidráulico JAMAR ${ }^{\circledR}$, estando a manopla ajustada na 2ª posição. Durante a realização do exame, os participantes foram orientados a se manterem sentados no banco regulável, de tal maneira que os quadris e joelhos permanecessem à 90으, estando os pés apoiados no chão. Com relação ao posicionamento do membro superior, o ombro manteve-se em posição aduzida junto ao tronco, o cotovelo à 900 com o antebraço em posição neutra (entre a pronação e supinação) e o punho na posição neutra sem que houvesse desvios, enquanto o examinador sustentava o dinamômetro, seguindo a recomendação da Sociedade Americana de Terapeutas de Mão - SATM ${ }^{11}$. Foram realizadas três repetições, alternando a movimentação para o teste, sendo inicialmente testada a mão direita e logo em seguida a esquerda.

\section{Testes cognitivos}

Foram realizados por meio da plataforma "Ubrain", incluindo as análises abaixo:

- Tarefa simples de tempo de reação (TRS): é uma tarefa simples de tempo de reação que mede a função psicomotora. O sujeito tinha que pressionar a tecla "J" o mais rápido possível quando um alvo aparecesse na tela. Esta tarefa terminou quando 35 respostas foram 
executadas. O tempo gasto entre a apresentação do estímulo e a resposta do atleta foi medido pelo sistema;

- Teste de reação de escolha (CRT): é uma tarefa de escolha de tempo de reação que requer atenção visual. O participante foi instruído a pressionar a tecla "J" se o destino exibido fosse vermelho e "F" se fosse azul. A tarefa terminou depois que 30 alvos foram exibidos. A precisão das respostas e o tempo médio gasto digitando a chave correta após o estímulo foram computados pelo sistema;

- Teste de memória episódica (EMT): é uma tarefa contínua de aprendizagem e reconhecimento que testa o reconhecimento visual episódico de memória e atenção. Nesta tarefa, o participante foi instruído a responder com a tecla "J" se o cartão que apareceu anteriormente aparecesse nesta tarefa e "F" se o cartão não aparecesse anteriormente. Letras com diferentes cores, números e símbolos foram exibidas. Há letras que foram repetidas várias vezes de forma aleatória e letras que foram repetidas apenas uma vez em 88 testes;

- Teste de memória de trabalho (WMT): avalia a memória de trabalho e a atenção. É um tradicional back test semelhante à tarefa EMT, em que o participante foi instruído a responder "J" se o cartão exibido fosse exatamente o cartão anterior ou "F" se o cartão exibido não correspondesse ao cartão anterior. Os cartões usados são diferentes daqueles da EMT para evitar confusão e foram necessárias 31 respostas para completar a tarefa.

\section{Protocolo de desidratação}

A desidratação dos atletas foi realizada por meio de exposições intermitentes a sessões de sauna úmida $\left(70^{\circ} \mathrm{C}\right)$ com a duração de trinta minutos. Estas foram intervaladas por períodos de cinco minutos, quando eram realizados os procedimentos de pesagem após a secagem com toalhas para eliminar o excesso de líquido. $O$ procedimento foi repetido até a redução de $3 \%$ do peso total dos participantes. O peso corporal dos atletas foi mensurado por meio de duas balanças digitais de vidro da marca Relaxmedic ${ }^{\oplus}$ e Multilaser ${ }^{\oplus}$, ambas com capacidade de $3 \mathrm{~kg}$ a $180 \mathrm{~kg}$ e graduação de $0,1 \mathrm{~kg}$.

Anteriormente à realização de qualquer procedimento metodológico, a presente pesquisa foi aprovada após análise do Comitê de Ética em Pesquisa do Centro Universitário de Brasília - UniCEUB, sob o parecer 3.706.656/19. 


\section{Análise dos dados}

Inicialmente a amostra foi distribuída pelo gênero, idade, dominância, peso e estatura. Foram então comparados os resultados das avaliações pré e pós-intervenção apresentando as diferenças em números absolutos e percentuais. Para analisar as diferenças encontradas nos resultados, foram calculadas as médias, mediana e o desvio padrão dos dados e realizado o teste estatístico de Wilcoxon pareado. Foi adotado o nível de significância de $5 \%$. 


\section{RESULTADOS E DISCUSSÃO}

A tabela 1 apresenta as características gerais da amostra. Foram avaliados 10 atletas, sendo 8 do sexo masculino e 2 do feminino. A média de idade dos participantes foi de 32,09 $\pm 6,34$ anos.

Tabela 1. Distribuição da amostra pelas características gerais - número de atletas, sexo, médias de idade (anos), peso $(\mathrm{kg})$, estatura $(\mathrm{cm}), \mathrm{IMC}\left(\mathrm{kg} / \mathrm{m}^{2}\right)$ e desvio padrão. Brasília/DF, 2019.

\begin{tabular}{cccccc}
\hline $\begin{array}{c}\text { Número } \\
\text { de atletas }\end{array}$ & Sexo & Idade & Peso & Estatura & IMC \\
\hline & Feminino $=$ & & Pré $=74,90 \pm$ & & Pré $=24,91 \pm$ \\
2 & & 9,24 & $170,10 \pm 8,99$ & 1,70 \\
10 & Masculino $=$ & $32 \pm 6,34$ & Pós $=72,74 \pm$ & & Pós $=24,90$ \\
& & 8,98 & & $\pm 1,74$ \\
\end{tabular}

\section{Peso, IMC e gordura corporal}

As tabelas 2 a 4 apresentam a evolução do peso, IMC e gordura corporal. Percebe-se que, em média, os atletas perderam 2,24kg com a intervenção, assim como houve diminuição do desvio padrão. Em relação ao IMC, este diminuiu apenas $0,01 \mathrm{~kg} / \mathrm{m} 2$ (tabela 3). 0 desvio padrão aumentou apenas em 0,04 unidades. Apesar de todos os quartis e o IMC máximo terem diminuído, o IMC mínimo aumentou.

Tabela 2. Evolução da variável peso do período pré para o pós intervenção. Brasília/DF, 2019.

\begin{tabular}{lll}
\hline Análise & $\begin{array}{l}\text { Pré-intervenção } \\
(\mathbf{k g})\end{array}$ & $\begin{array}{l}\text { Pós-intervenção } \\
(\mathbf{k g})\end{array}$ \\
\hline Média & 74,98 & 72,74 \\
Desvio padrão & 9,24 & 8,98 \\
Mínimo & 62 & 69 \\
1ㅇ Quartil & 67,55 & 65,59 \\
Mediana & 76,60 & 74,10 \\
3o Quartil & 82,10 & 79,50 \\
\hline
\end{tabular}


Tabela 3. Evolução da variável IMC do período pré para o pós intervenção. Brasília/DF, 2019.

\begin{tabular}{lll}
\hline Análise & $\begin{array}{l}\text { Pré-intervenção } \\
\left(\mathbf{k g} / \mathbf{m}^{\mathbf{2}}\right)\end{array}$ & $\begin{array}{l}\text { Pós-intervenção } \\
\left(\mathbf{k g} / \mathbf{m}^{\mathbf{2}}\right)\end{array}$ \\
\hline Média & 24,91 & 24,9 \\
Desvio padrão & 1,7 & 1,74 \\
Mínimo & 21,7 & 23 \\
1 Quartil & 24,1 & 23,85 \\
Mediana & 24,7 & 24,2 \\
3 Quartil & 25,75 & 25,5 \\
Máximo & 28,4 & 28,2 \\
\hline
\end{tabular}

Em relação à gordura corporal (tabela 4), foi possível observar que algumas medidas resumo são menores no período pós-intervenção, por exemplo a média e a mediana. Constatou-se que existem evidências estatísticas de que o percentual de gordura é, de fato, menor após a intervenção $(p=0,003)$. Tal diminuição, contudo, não representa relevância clínica.

Tabela 4. Evolução da variável gordura corporal do período pré para o pós intervenção. Brasília/DF, 2019.

\begin{tabular}{lll}
\hline Análise & $\begin{array}{l}\text { Pré-intervenção } \\
\text { (\% gordura) }\end{array}$ & $\begin{array}{l}\text { Pós-intervenção } \\
\text { (\% gordura) }\end{array}$ \\
\hline Média & 14,75 & 13,45 \\
Desvio padrão & 5,00 & 5,25 \\
Mínimo & 8,40 & 7,10 \\
1 Quartil & 11,20 & 9,65 \\
Mediana & 14,75 & 11,10 \\
3 Quartil & 19,45 & 18,00 \\
Máximo & 22,60 & 22,00 \\
\hline
\end{tabular}




\section{EAS}

\section{Densidade}

Notou-se que, apesar do pós-intervenção apresentar valores atípicos, as medidas de densidade pré e pós intervenção são bem próximas. Diante dessa indicação, estatisticamente, não houveram diferenças significantes entre os momentos ( $p$-valor 0,614 ).

pH

Não foram encontradas diferenças estatísticas pH pré e pós intervenção ( $p$-valor $0,05)$.

\section{Glicose urinária}

Como todas as observações foram iguais, conclui-se que o procedimento não levou a nenhuma alteração na glicose dos pacientes.

\section{Corpos cetônicos}

A distribuição das informações foi diferente em cada uma das fases. A média de corpos cetônicos pré intervenção foi de 0,045 e, na fase de pós-intervenção, esse valor subiu para 3,18. Assim como o desvio padrão, que passou de 1,51 para 6,03. Isto significa que, apesar de apresentar um aumento expressivo no valor da média pós intervenção, a variação da amostra teve valores mais variados. Além disso, como o $p$-valor obtido é igual a 0,97 , a intervenção eleva consideravelmente a média de corpos cetônicos na urina, porém não de maneira significativa visando estatística.

\section{Urobilinogênio}

Os atletas não obtiveram concentrações consideráveis antes da intervenção. Após a intervenção, apenas três indivíduos registraram níveis de urobilinogênio, o que não é suficiente para afirmar que existem diferenças nesta medida antes ou após a perda de peso.

\section{Bilirrubina}

Foi possível observar que não houve detecção da variável bilirrubina antes da intervenção. Após a perda de peso, houve o registro dessa variável em apenas um atleta. Portanto, não há evidencias de que essa variável seja diferente após a intervenção. 


\section{Hemoglobina urinária}

A hemoglobina urinária de todos os atletas pré intervenção registrada foi zero. Após a intervenção houve apenas um atleta cuja hemoglobina registrada foi +++/4+. Sendo assim, não há evidências de que esta foi alterada com a desidratação

\section{Nitrito}

Todas as observações coletadas, tanto para o momento pré-intervenção quanto para o pós-intervenção, tiverem seus resultados nulos.

\section{Leucócitos}

A média antes da perda de peso foi igual a 0,67 , inferior ao valor da média do momento pós-intervenção, de 1,89. Após análise estatística, o valor encontrado é significantemente maior no momento pós intervenção, não representando, porém, significância clinica.

\section{Bactérias}

Não houve nenhuma alteração no número de bactérias pré e pós intervenção - não detecção bacteriana em ambos os momentos.

\section{Cortisol salivar}

O comportamento do cortisol salivar foi similar nos dois estados, com a variável no momento após a intervenção apresentando um valor mediano levemente superior, porém sem significância estatística ( $p>0,05)$.

Tabela 5. Evolução da variável cortisol salivar do período pré para o pós intervenção. Brasília/DF, 2019.

\begin{tabular}{lll}
\hline Análise & $\begin{array}{l}\text { Pré-intervenção } \\
\text { (nmol/L) }\end{array}$ & $\begin{array}{l}\text { Pós-intervenção } \\
\text { (nmol/L) }\end{array}$ \\
\hline Média & 18,21 & 16,51 \\
Desvio padrão & 10,96 & 9,36 \\
Mínimo & 5,67 & 4,45 \\
1 Quartil & 9,83 & 7,63 \\
Mediana & 15,30 & 16,60
\end{tabular}


3 Quartil $\quad 24,90 \quad 23,45$

Máximo $\quad 39,10 \quad 29,30$

\section{Força de preensão palmar}

A média da força de preensão palmar diminuiu em ambos lados, comparando os resultados antes e após a intervenção (tabela 6). Apesar dos p-valores obtidos serem superiores (0,23 para o lado direito e 0,24 para o esquerdo) ao nível de significância definido anteriormente, a diminuição da média em valores absolutos $(6,13 \%$ no lado direito e $5,35 \%$ no esquerdo), pode impactar clinicamente, uma vez que demostra a tendência de perda de força após desidratação.

Tabela 6. Evolução da variável força de preensão palmar (kgf) do período pré para o pós intervenção. Brasília/DF, 2019.

\begin{tabular}{ccccc}
\hline Análise & Direito - Pré & Direito- Pós & Esquerdo - Pré & Esquerdo - Pós \\
\hline Média & 92 & 86,36 & 90,09 & 85,27 \\
Desvio padrão & 17,10 & 16,60 & 19,50 & 15,73 \\
Mínimo & 61 & 62 & 54 & 58 \\
1 Quartil & 81 & 74,50 & 77 & 76 \\
Mediana & 99 & 85 & 93 & 91 \\
3 Quartil & 100,5 & 98,5 & 101,5 & 98,5 \\
Máximo & 116 & 110 & 118 & 101 \\
Coeficientes de & $18,6 \%$ & $19,2 \%$ & $21,6 \%$ & $18,4 \%$ \\
Variação & & & & \\
\hline
\end{tabular}

\section{Testes Cognitivos}

\section{Reação simples}

Percebeu-se que esta variável apresentou resultados mais rápidos nos atletas antes da intervenção. Isso pode ser observado tanto pela média quanto pelos valores máximos e mínimos obtidos (Tabela 7). Esta reação, portanto, apresentou alterações estatisticamente 
significantes, revelando que, após a intervenção, os atletas tiveram um desempenho cognitivo mais lento neste teste cognitivo.

Tabela 7. Evolução da variável "Reação de escolha" no período pré e pós intervenção. Brasília, 2019.

\begin{tabular}{lll}
\hline Análise & $\begin{array}{l}\text { Pré-intervenção } \\
\text { (ms) }\end{array}$ & $\begin{array}{l}\text { Pós-intervenção } \\
\text { (ms) }\end{array}$ \\
\hline Média & 303,30 & 381,28 \\
Desvio Padrão & 23,99 & 167,82 \\
Máximo & 345,50 & 867,40 \\
Mínimo & 278,40 & 282,40 \\
\hline
\end{tabular}

\section{Reação de escolha}

Percebeu-se, de acordo com a Tabela 8, que a velocidade média de todos os atletas aumentou após a intervenção. Contudo, tais mudanças não se demonstraram estatisticamente significativas.

Tabela 8. Evolução da variável "Reação de escolha” no período pré e pós intervenção. Brasília, 2019.

\begin{tabular}{lll}
\hline Estatística & $\begin{array}{l}\text { Pré-intervenção } \\
\text { (ms) }\end{array}$ & $\begin{array}{l}\text { Pós-intervenção } \\
\text { (ms) }\end{array}$ \\
\hline Média & 480,37 & 527,99 \\
Desvio padrão & 70,00 & 113,37 \\
Mínimo & 397,53 & 410,38 \\
Máximo & 614,22 & 760,97 \\
\hline
\end{tabular}

\section{Memória operacional}

As médias dos dois estados encontradas foram próximas e nenhum valor discrepante foi identificado (Tabela 9), demonstrando que a intervenção não teve efeito sobre a memória operacional. 
Tabela 9. Evolução da variável "Memória operacional" no período pré e pós intervenção. Brasília, 2019.

\begin{tabular}{lll}
\hline Estatística & $\begin{array}{l}\text { Pré intervenção } \\
\text { (ms) }\end{array}$ & $\begin{array}{l}\text { Pós intervenção } \\
\text { (ms) }\end{array}$ \\
\hline Média & 894,05 & 762,77 \\
Desvio Padrão & 219,66 & 155,74 \\
Máximo & 1326,60 & 996,21 \\
Mínimo & 556,19 & 494,56 \\
\hline
\end{tabular}

A perda de peso por desidratação é uma prática comuns nos esportes de combate ${ }^{12}$. Segundo Lorenço-Lima e Hirabara ${ }^{13}$, os atletas geralmente se utilizam desta para adequar-se a uma categoria de peso que lhes traga vantagem, em grande parte das vezes inferior a seu peso "normal". Inúmeros estudos têm sugerido efeitos prejudiciais dessa prática em atletas ${ }^{14}$. A perda rápida de peso afeta diretamente a saúde fisiológica e cognitiva do atleta, podendo, inclusive, aumentar o risco de morte ${ }^{15}$. Diversas investigações relatam que atletas submetidos a esta prática apresentaram diminuição da memória de curto prazo, vigor, concentração e autoestima, bem como aumento da confusão, raiva, fadiga, depressão e isolamento ${ }^{16,17}$, os quais desequilibram a homeostase física e psicológica, prejudicando o desempenho competitivo ${ }^{15,18,17}$.

Verificou-se, no presente estudo, que a perda de peso aguda impactou em todas as áreas pesquisadas (física, comportamental e laboratorial). Percebeu-se um impacto significativo com relação a diminuição tempo de reação simples e, na urina, o aparecimento de leucócitos, cristais e corpos cetônicos. Com relação ao cortisol e à força de preensão palmar, houveram diferenças clinicamente impactantes, não apresentando, contudo, significância estatística.

O tempo de reação é um componente mensurável importante de nossa integração sensório-motora para o desempenho de distintas tarefas, sejam elas esportivas, profissionais ou atividades da vida diária ${ }^{13}$. Um tempo de reação prolongado pode comprometer totalmente a ação do sujeito caso a tarefa motora exija dele uma resposta imediata ao estímulo que the foi apresentado. Qualquer fator que prejudique ou beneficie a velocidade de processamento da informação, ainda que em milésimos de segundo, pode ser determinante 
no desempenho da tarefa motora ${ }^{19}$. Em esportes de combate, funções cognitivas, tal qual a força física, desempenham papeis cruciais, influenciando, inclusive, a probabilidade de vitória de um atleta ${ }^{12}$. Sendo assim, um tempo maior na variável reação simples após a desidratação prejudica consideravelmente o desempenho desportivo dos atletas, deixando os mesmos mais lentos, diminuindo o poder de tomada de decisão, podendo levar a queda do desempenho esportivo durante competições.

Vale ressaltar também, dentre os resultados, o surgimento de corpos cetônicos na urina dos atletas após desidratação. Tal fato decorre de um estado de cetose metabólica. Devido ao jejum prolongado e a desidratação, há diminuição dos níveis de glicose e insulina que eleva os níveis de glucagon. Esse hormônio, hiperglicemiante, promove lipólise cujos produtos finais são os corpos cetônicos, isto é, a acetona, o acetato e o beta-hidroxibutirato. Já foi demonstrado que uma perda de peso aguda em lutadores elevou significativamente os níveis de excreção de corpos cetônicos, em comparação a mesma perda em maior tempo e controlada $^{20}$. A cetose pode ser deletéria principalmente caso haja uma perda dos mecanismos compensatórios renais, causada, sobretudo, por hipovolemia severa, podendo ser atingida pela desidratação, por exemplo. Contudo, poucos são os estudos que correlacionam cetoacidose e seus efeitos com processos de perda de peso em atletas.

Ainda na urina dos atletas, vale lembrar que tanto o número de leucócitos quanto da concentração de cristais como urato amorfo e oxalato de cálcio pós intervenção apesar de estatisticamente apresentarem elevação considerável, mantiveram-se em valores fisiológicos. Sabe-se, entretanto, que o aumento da concentração de cristais urinários precede a formação de cálculos renais ${ }^{21}$. A prevalência da nefrolitíase está aumentando em todo o mundo e resulta em ônus significativo para o sistema de saúde. Novos estudos revelam que a formação de cálculos urinários está associada a várias morbidades graves ${ }^{22}$. Dessa forma, ainda são necessários estudos que correlacionam a prevalência de litíase renal em atletas e desidratação. Além disso, é importante constatar que apesar da perda de peso, a concentração de urina dos atletas não apresentou diferença de densidade. Esse resultado reforça a importância de um processo de desidratação controlado, uma vez que urinas muito concentradas, relatadas em urinas de atletas pós desidratação, demonstram hipovolemia, que em casos extremos é responsável por diversas alterações patológicas como, por exemplo, insuficiência renal aguda pré renal. 
Apesar de não demonstrar resultados estatisticamente relevantes em análise conjunta da variação de cortisol, uma análise individual demonstra a variabilidade desse hormônio na desidratação. Tal resultado é amplamente notificado na literatura ${ }^{23,24}$. Dois atletas demonstraram níveis elevados desse hormônio após a desidratação, tendo uma elevação percentual (400\% e 90\%) significativa comparado com seus níveis pré desidratação. Outro aspecto encontrado foi níveis acima dos valores de referência pré desidratação, normalizados após tal processo, visto em quatro atletas. Os níveis desse hormônio impactam diretamente processos de tomada de decisão, tendo sido encontrados em maiores níveis em atletas que perderam sua competição ${ }^{24}$. Percebe-se, entretanto, que a análise da elevação do cortisol realizada nesses atletas não pode limitar-se a óptica fisiológica, uma vez que diversos atletas relataram o stress psicológico que envolvia o processo de rápida perda de peso.

Ademais, a força de pressão manual dos atletas também apresentou mudanças importantes a serem enfatizadas. Durante a luta, o atleta se encontra em contato com o adversário na maior parte do tempo e, para manter essa posição, necessita realizar movimentos sucessivos de preensão, o que demonstra a importância de uma função muscular adequada para esse movimento específico ${ }^{11}$. Sendo assim, uma diminuição na média dos resultados dessa variável após a desidratação é crucial para um atleta e tem implicações diretas durante o combate, influenciando, portanto, na performance do lutador ${ }^{25}$.

Os demais resultados não demonstraram alterações. Esse fato demonstra que algumas mudanças fisiológicas e comportamentais são mais sensíveis à perda de peso, quando comparadas às supracitadas.

O presente estudo apresentou limitações a respeito da sua amostra e aplicação. A amostra contou apenas com dez atletas, isto é, um número limitado. Além disso, o estudo registrou apenas alterações agudas, podendo, assim, apresentar resultados que não são perpetuados ou se modificam, uma vez que a prática de perda de peso aguda é realizada pela grande maioria dos atletas de maneira recorrente.

É imprescindível ressaltar, porém, que o presente estudo possui aplicações clínicas de extrema relevância, uma vez que esportes de combate que agrupam atletas em faixas de peso têm grande estima mundial ${ }^{16} \mathrm{e}$, por consequência, as práticas de perda de peso aguda tornam-se cada vez mais frequentes, sendo desidratação a principal. Portanto, as alterações 
provocadas por esse processo, relatadas neste estudo, devem ser levadas em consideração, promovendo a saúde do atleta. 


\section{CONSIDERAÇÕES FINAIS}

A análise dos resultados demonstrou que após a desidratação em sauna úmida para a perda de peso em atletas profissionais de combate, houve uma diminuição significante da força de preensão manual e da variável cognitiva de reação simples, ou seja, após a intervenção os atletas ficaram mais lentos.

Desta forma é cada vez mais importante que esse assunto seja esclarecido e propagado entre os atletas, treinadores, produtores de evento, membros de comissões atléticas e profissionais da saúde, para que possam compreender os malefícios envolvidos no processo, que ultrapassam a perda de performance e impactam no futuro dos competidores. 


\section{REFERÊNCIAS}

1. Gutmann A. From ritual to record: the nature of modern sports. New York: Columbia University Press; 1978.

2. Poliakoff MB. Combat sports in the Ancient World: competition, violence, and culture. London: Yale University Press; 1987.

3. São Paulo. Secretaria Municial de Esportes e Lazer. Compreensões e características comuns na família das Artes Marciais e Esportes de Combate. In: São Paulo. Secretaria Municial de Esportes e Lazer. Guia Didático Artes Marciais e Esportes de Combate (Versão preliminar). São Paulo: Prefeitura de São Paulo; 2013 [acesso em 2020 fev 21]. p. 8-12. Disponível

em: https://www.prefeitura.sp.gov.br/cidade/secretarias/upload/esportes/artesmarciais.pdf.

4. Souza CK de S, Abreu ES de. Considerações sobre o comportamento de competidores de judô e jiu-jitsu para rápida perda de peso pré-competição. Demetra: Alimentação, Nutrição \& Saúde [Internet]. 2017 [acesso em 2020 fev 27]; 12(1):5-20. Disponível em: https://www.e-publicacoes.uerj.br/index.php/demetra/article/download/22327/20055.

5. Hirschbruch MD, Carvalho JR. Nutrição Esportiva. Tamboré Barueri: Manole; 2002.

6. Santos FR, Navarro F, Donatto FF, IDE BN. Avaliação do perfil nutricional de atletas praticantes de Jiu-Jitsu. Revista Brasileira de Nutriçao Esportiva. 2011; 5(27):3.

7. Artioli GG, Franchini E, Lancha Junior, AH. Perda de peso em esportes de combate de domínio: revisão e recomendações aplicadas. Revista Brasileira de Cineantropometria \& Desempenho Humano. 2006; 8(2):91-101.

8. Khodaee M, Olewinski L, Shadgan B, Kiningham RR. Rapid Weight Loss in Sports with Weight Classes. Current Sports Medicine Reports [Internet]. 2015 [acesso em 2020 fev 20]; 19(1): 435-441. Disponível em: https://pdfs.semanticscholar.org/412a/60cc4131fa5f486c48159b707175d531a285.

9. Nascimento AV do, Costa R F da. Efeitos da perda de peso e desidratação no desempenho de atletas de artes marciais. Nutrição Brasil [Internet]. 2017 [acesso em 2020 fev 10]; 3(16):1-9. Disponível em: http://www.portalatlanticaeditora.com.br/index.php/nutricaobrasil/article/view/1107/2 174.

10. Darby D, Moriarity J, Pietrzak R, Kutcher J. Prediction of winning amateur boxers using pretournament reaction times. J Sports Med Phys Fitness. 2014; 1(54):340-6.

11. Lorenço-Lima $L$ de, Hirabara SM. Efeitos da perda rápida de peso em atletas de combate. Rev. Bras. Ciênc. Esporte [Internet]. 2013 [acesso em 2020 ago 3]; 1(35):245-260. Disponível em: https://www.scielo.br/pdf/rbce/v35n1/a18v35n1.pdf.

12. Irwin C, Campagnolo N, ludakhina E, Cox GR, Desbrow B. Effects of acute exercise, dehydration and rehydration on cognitive function in well-trained athletes. Journal of Sports Sciences [Internet]. 2017 [acesso em 2020 ago 3]; 36(3):247-255. Informa UK Limited. http://dx.doi.org/10.1080/02640414.2017.1298828. Disponível em: https://pubmed.ncbi.nlm.nih.gov/28282741/.

13. Franchini E, Brito CJ, Artioli GG. Weight loss in combat sports: physiological, psychological and performance effects. Journal of the international society of sports nutrition. 2012; $9(1) ; 52$. 
14. Steen SN, Brownell KD: Patterns of weight loss and regain in wrestlers: has the tradition changed. Med Sci Sports Exerc. 1990; 22: 762-768.

15. Irfan Y. Associations Among Dehydration, Testosterone and Stress Hormones in Terms of Body Weight Loss Before Competition. The American Journal Of The Medical Sciences. 2012; 2(350):103-108.

16. Jetton AM, Lawrence MM, Meucci M, Haines TL, Collier SR, Morris DM et al. Dehydration and Acute Weight Gain in Mixed Martial Arts Fighters Before Competition. Journal Of Strength And Conditioning Research [Internet]. 2013 [acesso em 2020 ago 3]; 27(5):13221326. Disponível em: https://pubmed.ncbi.nlm.nih.gov/23439336/.

17. Marques Junior NK. Tempo de reação no esporte: uma revisão. Lecturas: Educación Física y Deporte. 2011[acesso em 2020 ago 3]; 1(1):1-9. Disponível em: https://www.researchgate.net/publication/237066966_Tempo_de_Reacao_no_Esporte.

18. Sebben S, Brum SPB. Urolitíase e fatores associados. Arquivos Catarinenses de Medicina. 2007: 99-106.

19. Pachaly MA, Baena CP, Carvalho M de. Therapy of nephrolithiasis: where is the evidence from clinical trials? Jornal Brasileiro de Nefrologia. 2016; 38(1):99-106.

20. Castro-Sepulveda M, Ramirez-Campillo R, Abad-Colil F, Monje C, Peñailillo L, Cancino J et al. Basal Mild Dehydration Increase Salivary Cortisol After a Friendly Match in Young Elite Soccer Players. Frontiers In Physiology [Internet]. 2018 [acesso em 2020 ago 3]; 9(1):1-5. Disponível em: https://pubmed.ncbi.nlm.nih.gov/30319450/.

21. López-Samanes A, Pallarés JG, Pérez-Lopes A, Mora-Rodríguez R, Ortega JF. Hormonal and neuromuscular responses during a singles match in male professional tennis players. Plos One[Internet]. 2018 [acesso em 2020 ago 3];4(13):1-13. Disponível em: https://www.ncbi.nlm.nih.gov/pmc/articles/PMC5889166/pdf/pone.0195242.pdf.

22. Barley OR, Iredale F, Chapman DW, Hopper A, Abbiss C R. Repeat Effort Performance Is Reduced 24 Hours After Acute Dehydration in Mixed Martial Arts Athletes. Journal Of Strength And Conditioning Research [Internet]. 2018 [acesso em 2020 ago 3]; 32(9):25552561. Disponível em: https://pubmed.ncbi.nlm.nih.gov/28930879/.

23. Bu B, Haijun H, Yong L, Chaohui Z, Xiaoyuan Y, Singh MF. Effects of martial arts on health status: a systematic review. Journal of Evidence-Based Medicine. 2010; 3(4): 205-219

24. Gracie R, Gracie C. Brazilian Jiu-Jitsu: Theory and Technique. With Kid Peligro. 2000.

25. Kiningham RB, Gorenflo DW. Weight loss methods of high school wrestlers. Medicine and science in sports and exercise. 2001; 33(5):810-813.

26. Maughan RJ, Shirreffs SM. Dehydration and rehydration in competative sport. Scandinavian Journal Of Medicine \& Science In Sports [Internet]. 2010 [acesso em 2020 ago 3]; 20:40-47. Disponível em: https://pubmed.ncbi.nlm.nih.gov/21029189/.

27. Oppliger RA, Casa HS, Horswill, Landry GL, Shelter AC. American College of Sports Medicine position stand. Weight loss in wrestlers. Medicine and science in sports and exercise. 1996; 28 (6):ix-xii.

28. Padilha DA, Ide BN. Possíveis lesões decorrentes da aplicação das técnicas do jiu-jitsu desportivo. Lecturas: Educación física y deportes; 2005.

29. Horswill CA, Park SH, Roemmich JN. Changes in the protein nutritional status of adolescent wrestlers. Med Sci Sports Exerc. 1990, 22: 599-604.

30. Filaire E, Maso F, Degoutte F, Jouanel P, Lac G: Food restriction, performance, psychological state and lipid values in judo athletes. Int J Sports Med. 2001, 22: 454-459.

31. Umeda T, Nakaji S, Shimoyama T, Yamamoto Y, Totsuka M, Sugawara K: Adverse effects of energy restriction on myogenic enzymes in judoists. J Sports Sci. 2004, 22: 329-338. 10. 
32. Degoutte F, Jouanel P, Begue RJ, Colombier M, Lac G, Pequignot JM, Filaire E: Food restriction, performance, biochemical, psychological, and endocrine changes in judo athletes. Int J Sports Med. 2006, 27: 9-18.

33. Guedes DP. Procedimentos clínicos utilizados para análise da composição corporal. Revista Brasileira de Cineantropometria e Desempenho Humano. 2012; 15(1):113-129.

34. Oliveira M, Moreira D, Godoy JRP, Cambraia AN. Avaliação da força de preensão palmar em atletas de jiu-jitsu de nível competitivo. R. bras. Ci e Mov. 2006; 14(3): 63-70.

35. Khodaee M, Olewinski L, Shadgan B, Kiningham RR. Rapid Weight Loss in Sports with Weight Classes. Current Sports Medicine Reports. 2015; 19(1): 435-441.

36. Nascimento AV do, Costa R F da. Efeitos da perda de peso e desidratação no desempenho de atletas de artes marciais. Nutrição Brasil. 2017; 3(16):1-9.

37. Souza CK de S, Abreu ES de. Considerações sobre o comportamento de competidores de judô e jiu-jitsu para rápida perda de peso pré-competição. Demetra: Alimentação, Nutrição \& Saúde. 2017; 12(1):5-20.

38. Kim S, Greenwell TC, Andrew DPS, Lee J, Mahony DF: An analysis of spectator motives in an individual combat sport: a study of mixed martial arts fans. Sport Mark Q 2008, 17:109119.

39. ARTIOLI, Guilherme Giannini; GUALANO, Bruno; FRANCHINI, Emerson; SCAGLIUSI, Fernanda Baeza; TAKESIAN, Mariane; FUCHS, Marina; LANCHA, Antonio Herbert. Prevalence, Magnitude, and Methods of Rapid Weight Loss among Judo Competitors. Medicine \& Science In Sports \& Exercise, [S.L.], v. 42, n. 3, p. 436-442, mar. 2010. Ovid Technologies (Wolters Kluwer Health). http://dx.doi.org/10.1249/mss.0b013e3181ba8055.

40. HOUSTON, Michael E.; MARRIN, Donald A.; GREEN, Howard J.; THOMSON, James A.. The Effect of Rapid Weight Loss on Physiological Functions in Wrestlers. The Physician And Sportsmedicine, [S.L.], v. 9, n. 11, p. 73-78, nov. 1981. Informa UK Limited. http://dx.doi.org/10.1080/00913847.1981.11711208.

41. LAKICEVIC, Nemanja; ROKLICER, Roberto; BIANCO, Antonino; MANI, Diba; PAOLI, Antonio; TRIVIC, Tatjana; OSTOJIC, Sergej M.; MILOVANCEV, Aleksandra; MAKSIMOVIC, Nebojsa; DRID, Patrik. Effects of Rapid Weight Loss on Judo Athletes: a systematic review. Nutrients, [S.L.], v. 12, n. 5, p. 1220-1237, 26 abr. 2020. MDPI AG. http://dx.doi.org/10.3390/nu12051220.

42. Clarys $P$, Ramon $K$, Hagman F, Deriemaeker $P$, Zinzen $E$. Influence of weight reduction on physical performance capacity in judokas. Journal of Combat Sports and Martial Arts. 2010;1(2):71-76.

43. PINTO, Hyago Furtado de Oliveira; MÖLLER, Gabriella Berwig; ALVES, Fernanda Donner. AVALIAÇÃO DE CONDUTAS PARA PERDA DE PESO PRÉ-COMPETIÇÃO DE JOVENS ATLETAS DE JUDÔ. Revista Brasileira de Nutrição Esportiva, Brasil, v. 13, n. 82, p. 848-853, dez. 2019.

44. FÉLIX, Nathália Carneiro de Castro; CHAVES, Daniela Fojo Seixas. Efeitos da desidratação para redução rápida de peso na performance e saúde de atletas de luta. Revista Brasileira de Nutrição Funcional, Rio de Janeiro, v. 6, n. 15, p. 16-22, mar. 2015. 